\title{
Otras neoplasias: donante vivo y receptor
}

\author{
Other malignancies: living donor and recipient \\ Carmen Gracida-Juárez* \\ * Cirugía de Trasplantes. \\ Ex-jefa del Departamento de Trasplantes del Hospital de Especialidades del Centro Médico Nacional Siglo XXI, IMSS.
}

\section{DONANTE VIVO}

1. Los donadores renales vivos con un cáncer activo deben descartarse para la donación.

2. Los potenciales donadores con cáncer controlado y bajo riesgo de transmisión pueden considerarse para la donación de acuerdo con el Centro de Trasplantes, considerando el tipo de cáncer y el riesgo de transmisión.

3. Los potenciales donadores con cáncer de alto riesgo de transmisión y/o recurrencia deben cumplir un plazo de espera adecuado de acuerdo con el tipo de tumor para ser considerados como donadores; además, deberán ser evaluados por el oncólogo. Preferiblemente se deberá buscar otro donador.

4. Todos los formatos de consentimiento informado deben incluir la posibilidad de transmisión de cáncer a través de un donante vivo.

El trasplante de órganos es la mejor alternativa para la falla orgánica irreversible. Cada año se extiende la vida a miles de pacientes sin ningún riesgo, la mayor necesidad de órganos y la escasez de los mismos ha permitido mayor flexibilidad en los criterios de selección de potenciales donadores y receptores, esta situación ha permitido la transmisión no intencionada de patologías a través de órganos donados, predominantemente de donador fallecido. La transmisión de cáncer a través de un órgano donado o la aparición de cáncer en el receptor posterior al trasplante es un evento inesperado y trágico, ya que en muchas ocasiones disminuye la calidad de vida del receptor, con la consecuente pérdida del injerto e incluso puede acortar su vida. ${ }^{1}$
El cáncer es una de las principales causas de muerte en receptores de trasplante, la incidencia de cáncer se incrementa de dos a tres veces más en comparación con la población general. ${ }^{2,3}$ Existen diversos factores que favorecen el incremento de cáncer, entre ellos se encuentran: la inmunosupresión, la edad del receptor, el tipo de donador, la preexistencia de cáncer, la exposición al sol, las enfermedades virales y la transmisión de un cáncer preexistente en el donador. $^{3}$

Evaluación del donante vivo de riñón. El objetivo principal del estudio del donador vivo es la detección de patologías que puedan ser resueltas previo a la donación si es necesario y que no contraindiquen la misma, además de detectar otras patologías como son infecciones virales y patologías como cáncer que potencialmente son transmisibles a través del riñón donado.

Todos los donadores vivos deben tener una historia clínica exhaustiva. El objetivo principal de la identificación de cáncer en el donante vivo es proteger la salud del mismo, ya que reducir su función renal con la donación puede comprometerlo con tratamientos nefrotóxicos o efectos secundarios a quimioterapia y radioterapia; el segundo objetivo es evitar la transmisión de cáncer de un donador vivo a un receptor (Tabla 1).1,2,4

El cáncer es el gran reto en salud pública. La historia de cáncer en el donante vivo o donante fallecido no debe pasarse por alto, ya que el cáncer como causa de mortalidad a nivel mundial ha incrementado; en México no es la excepción, es la tercera causa de muerte sólo por debajo de las enfermedades cardia- 
Tabla 1: Riesgo de transmisión para tumores específicos en donadores.

\begin{tabular}{|c|c|}
\hline $\begin{array}{l}\text { Categoría de } \\
\text { riesgo }\end{array}$ & Tumores \\
\hline $\begin{array}{l}\text { Sin riesgo } \\
\text { significativo }\end{array}$ & Tumores benignos con potencial asociado con malignidades \\
\hline $\begin{array}{l}\text { Riesgo míni- } \\
\text { mo (<0.1\% de } \\
\text { transmisión) }\end{array}$ & $\begin{array}{l}\text { Cáncer de células basales de piel } \\
\text { Carcinoma de células escamosas sin metástasis } \\
\text { Carcinoma in situ de cérvix } \\
\text { Carcinoma in situ de cuerdas vocales } \\
\text { Carcinoma superficial de vejiga urinaria (TONOMO) } \\
\text { Carcinoma papilar solitario de tiroides }<0.5 \mathrm{~cm} \\
\text { Carcinoma folicular de tiroides mínimamente invasivo }<1 \mathrm{~cm}\end{array}$ \\
\hline $\begin{array}{l}\text { Bajo riesgo } \\
\text { (1-1\% de } \\
\text { transmisión) }\end{array}$ & $\begin{array}{l}\text { Carcinoma de células renales solitario resecado, bien } \\
\text { diferenciado }<1 \mathrm{~cm} \text { (Fuhrman } 1-2 \text { ) } \\
\text { Carcinoma de células renales solitario }>1 \mathrm{~cm}<2.5 \mathrm{~cm} \text { bien } \\
\text { diferenciado (Fuhrman } 1-2 \text { ) } \\
\text { Carcinoma papilar de tiroides solitario } 0.5-2 \mathrm{~cm} \\
\text { Carcinoma folicular de tiroides mínimamente invasivo } \\
\text { 1.0-2.0 cm } \\
\text { Teratoma maduro primario de SNC }\end{array}$ \\
\hline $\begin{array}{l}\text { Riesgo } \\
\text { intermedio } \\
\text { (1-10\% de } \\
\text { transmisión) }\end{array}$ & $\begin{array}{l}\text { Carcinoma de mama in situ }(\mathrm{E}-0) \\
\text { Carcinoma in situ de colon ( } \mathrm{E}-0 \text { ) } \\
\text { Historia de tumor maligno de SNC tratado (> } 5 \text { años previo) } \\
\text { con posibilidad de cura entre } 90 \text { a } 99 \%\end{array}$ \\
\hline $\begin{array}{l}\text { Alto riesgo } \\
\text { (transmisión } \\
\text { de }>10 \% \text { ) }\end{array}$ & $\begin{array}{l}\text { Melanoma maligno } \\
\text { Cáncer de mama > E } 0 \text { (activo) } \\
\text { Cáncer de colon E > } 0 \text { (activo) } \\
\text { Coriocarcinoma } \\
\text { Cáncer de SNC con derivación ventriculoperitoneal o } \\
\text { ventriculoatrial o metástasis extra SNC } \\
\text { Cáncer de SNC grado III o IV de la OMS } \\
\text { Leucemia o linfoma } \\
\text { Historia de melanoma, leucemia o linfoma, tumor de células } \\
\text { pequeñas de pulmón, carcinoma neuroendocrino, historia } \\
\text { de tumor de SNC no tratado considerado incurable con } \\
\text { posibilidades de cura < a } 90 \% \\
\text { Carcinoma metastásico } \\
\text { Sarcoma } \\
\text { Cáncer pulmonar E (I-IV) } \\
\text { Cáncer neuroendocrino de células pequeñas cualquiera } \\
\text { que sea su origen } \\
\text { Cualquier cáncer activo }\end{array}$ \\
\hline
\end{tabular}

SNC = Sistema Nervioso Central

Adaptado de: Nalesnik MA, Woodle ES, DiMaio JM, Vasudev B, Teperman LW, Covington S et al. Donor-transmitted malignancies in organ transplantation: assessment of clinical risk. Am J Transplant. 2011; 11: 1140-1147. ${ }^{1}$

cas, la diabetes y sus complicaciones. En los donantes de sexo femenino, con vida sexual activa, se deben descartar lesiones del cuello uterino y tumoraciones en glándulas mamarias, ya que estos dos tipos de cán- cer son las principales causas de muerte por cáncer en el sexo femenino a nivel global y en México estos últimos constituyen $25.7 \%$ en la población femenina; asimismo, se debe descartar cáncer de ovario, el cual ha ido en aumento en nuestro país. ${ }^{5,6}$

En donadores de sexo masculino mayores de 40 años se debe descartar cáncer de próstata, cáncer testicular y otros tipos de cáncer que han incrementado en la población mexicana, al igual que en la población mundial como son el cáncer de pulmón y el cáncer colorrectal. $4,7,8$ Se enfatiza la posibilidad de considerar que la aparición de cáncer en el receptor en un lapso menor a un año de trasplante es muy probable que provenga del donador. ${ }^{1}$ El diagnóstico o sospecha de melanoma es de vital importancia, ya que el riesgo de transmisión es alto..$^{1-4}$

\section{ESTUDIOS DE ESCRUTINIO PARA CÁNCER EN EL DONANTE VIVO}

El protocolo de estudio de los donadores vivos puede variar de acuerdo con cada Centro de Trasplantes, en los estudios de rutina se sugiere que no falten los siguientes estudios:

1. Radiografía de tórax. (Altamente recomendable).

2. Ultrasonido abdominal completo. (Altamente recomendable).

3. En sexo femenino colposcopia y citología cervical, antes de los 45 años ultrasonido mamario bilateral, después de los 45 años mastografía bilateral y/o ultrasonido mamario bilateral. (Altamente recomendable).

4. En sexo masculino, después de los 40 años de edad antígeno prostático específico. (Altamente recomendable).

5. En caso de lesiones de piel que sean sospechosas se sugiere toma de biopsia. (Altamente recomendable).

6. Otros estudios en caso de sospecha de algún cáncer y/o envío con el oncólogo.

\section{EVALUACIÓN DEL POTENCIAL RECEPTOR}

1. Es contraindicación absoluta para el trasplante tener cáncer activo; entre ellos mieloma múltiple, cáncer mamario (III-IV), cáncer colorrectal (D), cáncer de próstata (G4 o 5, T3c,T4,N+M+).

2. La mayoría de los pacientes con tumores malignos aun con tratamiento requieren un periodo de espera entre dos a cinco años para ser trasplantados (Tablas 2 y 3). 
3. Pacientes por cánceres in situ que han sido tratados no requieren tiempo de espera. ${ }^{1-3}$

El protocolo de estudio del potencial receptor, difícilmente será diferente al de otros pacientes de la población general, a excepción de encontrar factores de riesgo durante la historia clínica y/o hallazgos durante la exploración clínica o en los estudios de escrutinio. ${ }^{2,3}$

La decisión del trasplante con un cáncer preexistente puede resultar difícil y debe ser individualizada de acuerdo al tipo de cáncer, al estadio del mismo y al tiempo de evolución, todo esto debe discutirse por cada Centro de Trasplantes. Durante los estudios de protocolo se debe considerar los antecedentes here-

Tabla 2: Contraindicación y periodos de espera en receptores de trasplante renal y cáncer preexistente.

\begin{tabular}{ll}
\hline Tipo de cáncer & $\begin{array}{c}\text { Periodo de espera } \\
\text { para trasplante }\end{array}$ \\
\hline Cáncer no tratado & $\begin{array}{l}\text { Contraindicación } \\
\text { absoluta }\end{array}$ \\
Cáncer de mama estadio III y IV & \\
Cáncer colorrectal estadio D & \\
Cáncer de próstata G4 0 5, T3c,T4,N+M+ & No requiere tiempo de \\
Cáncer de próstata focal microscópico & espera \\
Cáncer renal incidentalmente detectado T1 & \\
Cáncer superficial de vejiga & Dos años de espera \\
Cáncer invasivo de vejiga & \\
Cáncer de mama in situ & \\
Cáncer cervical localizado & \\
Cáncer colorrectal estadio Duke A y B1 & \\
Linfoma de Hodgkin, linfoma no Hodgkin, enfer- & \\
medad linfoproliferativa postrasplante (segundo & \\
trasplante) & \\
Melanoma in situ & \\
Cáncer de pulmón & \\
Cáncer de próstata & \\
Cáncer testicular & \\
Cáncer de tiroides & \\
Tumor de Wilms (algunos refieren un año & \\
como suficiente) & \\
Cáncer de mama estadio II \\
Cáncer cervicouterino extendido (no in situ) \\
Cáncer colorrectal estadio C \\
Melanoma \\
Cáncer de células renales invasivo
\end{tabular}

Adaptado de: Sprangers B, Nair V, Launay-Vacher V, Riella LV, Jhaveri KD. Risk factors associated with post-kidney transplant malignancies: an article from the Cancer-Kidney International Network. Clin Kidney J. 2018; 11 (3): 315-329. ${ }^{\text {? }}$ ditarios y familiares, causas de cirugías previas, hacer detección de cáncer de glándula mamaria, cáncer cervicouterino, cáncer de próstata, cáncer colorrectal y cáncer de pulmón.

Es importante no ignorar las diferentes guías existentes de cáncer preexistente en el receptor de trasplante, ya que adelantar el trasplante no sólo no beneficiará al receptor, puede llevar a la consecuente pérdida del riñón trasplantado y acortar la vida. Todas las lesiones en piel sospechosas deben tener biopsia, existen consensos de expertos en lesiones de piel y trasplante que han emitido sus recomendaciones. ${ }^{3}$

Se sugiere realizar un registro de cáncer y trasplante en México, tal como ya existe en diferentes países.

Cada Centro de Trasplantes individualiza su protocolo de estudio de los potenciales receptores, sin embargo, existen estudios que se sugiere no deben obviarse en el protocolo.

1. Historia clínica completa.

2. Radiografía de tórax. (Altamente recomendable).

3. Ultrasonido abdominal completo. (Altamente recomendable).

4. En sexo femenino colposcopia y citología de cérvix, menores de 40 años ultrasonido mamario bilateral, mayores de 40 años mastografía bilateral y/o ultrasonido mamario bilateral. (Altamente recomendable).

5. En sexo masculino mayor a 40 años antígeno prostático específico. (Altamente recomendable).

6. Se recomienda el escrutinio de serologías de hepatitis $\mathrm{B}$ y $\mathrm{C}$ en todos los candidatos a trasplante.

7. Se sugiere citología urinaria para detección de cáncer urotelial y cistoscopia en caso de ser positiva la citología. (Recomendable).

8. Sangre oculta en heces. (Altamente recomendable).

9. Rectosigmoidoscopia. (Recomendable). ${ }^{2,3}$

\section{RECOMENDACIONES DESPUÉS DEL TRASPLANTE}

1. Considerar múltiples factores: tipo y estadio del tumor, órgano trasplantado, comorbilidades, tiempo después del trasplante, inmunosupresión y decisión del receptor.

2. Trasplantectomía de riñón (en etapa temprana).

3. En presencia de metástasis: valorar trasplantectomía y retiro de inmunosupresores, alternativamente reducción de la inmunosupresión y evaluar inicio de iMTor., ${ }^{2,3}$ 
Tabla 3: Recomendaciones en cáncer de piel preexistente en receptores de trasplante renal.

Recomendaciones de tiempo de espera para cáncer de piel

\begin{tabular}{|c|c|}
\hline $\begin{array}{l}\text { Carcinoma escamocelular (CEC) } \\
\text { de bajo riesgo y tratado }\end{array}$ & No requiere tiempo de espera \\
\hline $\begin{array}{l}\text { CEC de alto riesgo sin invasión } \\
\text { perineural con cirugía excisional }\end{array}$ & Requiere dos años de espera \\
\hline $\begin{array}{l}\text { CEC de alto riesgo con invasión } \\
\text { perineural tratado }\end{array}$ & Requiere de dos a tres años de espera \\
\hline $\begin{array}{l}\text { CEC de alto riesgo con metástasis } \\
\text { locales }\end{array}$ & Requiere 5 años de espera \\
\hline CEC con metástasis a distancia & $\begin{array}{l}\text { No es elegible para trasplante, referir a } \\
\text { oncología }\end{array}$ \\
\hline $\begin{array}{l}\text { Carcinoma de células de Merkel } \\
\text { (CCM) local sin ganglio centinela, } \\
\text { con excisión amplia }\end{array}$ & Requiere dos años de espera \\
\hline $\begin{array}{l}\text { CCM con metástasis ganglionar, } \\
\text { excisión amplia, disección } \\
\text { ganglionar y radioterapia }\end{array}$ & Requiere 3 a 5 años de espera \\
\hline CCM con metástasis a distancia & $\begin{array}{l}\text { No es elegible para trasplante, referir } \\
\text { a oncología }\end{array}$ \\
\hline $\begin{array}{l}\text { Melanoma in situ, con amplia } \\
\text { excisión }\end{array}$ & $\begin{array}{l}\text { No requiere tiempo de espera, requie- } \\
\text { re vigilancia cercana postrasplante }\end{array}$ \\
\hline Melanoma la con excisión amplia & Requiere dos años de espera \\
\hline $\begin{array}{l}\text { Melanoma lb/lla con excisión am- } \\
\text { plia con ganglio centinela o no }\end{array}$ & Requiere dos a cinco años de espera \\
\hline $\begin{array}{l}\text { Melanoma Ilb/llc con excisión amplia } \\
\text { con ganglio centinela }\end{array}$ & Requiere 5 años de espera \\
\hline Melanoma III o IV & $\begin{array}{l}\text { No es elegible para trasplante, referir } \\
\text { a oncología }\end{array}$ \\
\hline
\end{tabular}

Adaptado de: Zwald F, Leitenberger J, Zeitouni N, Soon S, Brewer J, Arron S et al. Recommendations for solid organ transplantation for transplant candidates with a pretransplant diagnosis of cutaneous squamous cell carcinoma, merkel cell carcinoma and melanoma: a consensus opinion from the International Transplant Skin Cancer Collaborative (ITSCC). Am J Transplant. 2016; 16 (2): $407-413 .{ }^{8}$

En México no existen reportes de transmisión de cáncer a través de un donador vivo, se han reportado series de pacientes con linfoma posterior al trasplante renal en las que se describen seis pacientes con linfoma en una revisión de enero de 1992 a junio de 2000 con un total de 629 pacientes, sólo uno de ellos tuvo diagnóstico antes de un año posterior al trasplante. ${ }^{9}$ Un reporte aislado de trasplante renal exitoso simultáneo con trasplante de médula ósea en pacientes con mieloma múltiple en el que se describió el caso de una paciente de 54 años diagnosticada inicialmente como insuficiencia renal y posteriormente diagnosticada con mieloma múltiple como causante de daño renal, la paciente recibió trasplante autólogo de células hematopoyéticas y un año posterior trasplante renal con éxito. ${ }^{10}$

\section{DISCUSIÓN}

La transmisión de cáncer a través de un donador vivo es un evento muy desafortunado, que sucede raras ocasiones, ya que miles de pacientes se trasplantan con éxito a nivel mundial sin ningún riesgo, lo que se hace obligatorio pensar en la posibilidad de transmisión de cáncer a través de un donante vivo o donante fallecido, así como pensar en la preexistencia de cáncer en el receptor y hacer diagnóstico. Se sugiere no ignorar guías de cáncer y trasplante ya publicadas para tomar la mejor decisión para los pacientes, evitando riesgos al donador vivo y riesgos al receptor. ${ }^{1-3}$

\section{REFERENCIAS}

1. Nalesnik MA, Woodle ES, DiMaio JM, Vasudev B, Teperman LW, Covington S et al. Donor-transmitted malignancies in organ transplantation: assessment of clinical risk. Am J Transplant. 2011; 11: 1140-1147.

2. Lentine KL, Kasiske BL, Levey AS, Adams PL, Alberú J, Bakr MA et al. KDIGO Clinical Practice Guideline on the Evaluation and Care of Living Kidney Donors. Transplantation. 2017; 101 (8S Suppl 1): S1-S109.

3. European Renal Best Practice Transplantation Guideline Development Group. ERBP guideline on the management and evaluation of the kidney donor and recipient. Nephrol Dial Transplant. 2013; 28 Suppl 2: ii1-71.

4. Blumberg EA. Creating a safer donor: a quarter century of progress? Am J Transplant. 2011; 11 (6): 1117-1118.

5. Reynoso-Noverón N, Torres-Domínguez JA. Epidemiologia del cáncer en México: carga global y proyecciones 2000-2020. Revista Latinoamericana de Medicina Conductual. 2018; 8 (1): 9-15.

6. GBD 2017 Causes of Death Collaborators. Global, regional, and national age-sex-specific mortality for 282 causes of death in 195 countries and territories, 1980-2017: a systematic analysis for the Global Burden of Disease Study 2017. Lancet. 2018; 392 (10159): 1736-1788.

7. Sprangers B, Nair V, Launay-Vacher V, Riella LV, Jhaveri KD. Risk factors associated with post-kidney transplant malignancies: an article from the Cancer-Kidney International Network. Clin Kidney J. 2018; 11 (3): 315-329.

8. Zwald F, Leitenberger J, Zeitouni N, Soon S, Brewer J, Arron $S$ et al. Recommendations for solid organ transplantation for transplant candidates with a pretransplant diagnosis of cutaneous squamous cell carcinoma, merkel cell carcinoma and melanoma: a consensus opinion from the International Transplant Skin Cancer Collaborative (ITSCC). Am J Transplant. 2016; 16 (2): 407-413.

9. Melchor JL, Cancino J, Gracida C. Lymphoproliferative disorders following kidney transplantation. Transplant Proc. 2002; 34 (7): 2537-2538.

10. Ruiz-Delgado GJ, León-Peña AA, Medina Ceballos E, VargasEspinoza J, León-González M, Ruiz-Arguelles GJ. Double transplant in a patient with multiple myeloma: bone marrow and kidney. Rev Hematol Mex. 2015; 16: 333-337.

Correspondencia:

Dra. Carmen Gracida-Juárez

E-mail: mcgracida@gmail.com 